\title{
Luminescence imaging of leaf damage induced by lipid peroxidation products and its modulation by $\beta$-cyclocitral
}

\author{
Marek Rac ${ }^{1,2}$ | Leonard Shumbe ${ }^{1}$ | Camille Oger ${ }^{3}$ | Alexandre Guy ${ }^{3}$ | \\ Claire Vigor $^{3}$ | Brigitte Ksas ${ }^{1}$ | Thierry Durand ${ }^{3}$ | Michel Havaux ${ }^{1}$
}

\author{
${ }^{1}$ Institute of Biosciences and Biotechnologies, \\ CEA/Cadarache, Aix Marseille University, CEA, \\ CNRS, BIAM, UMR7265, Saint-Paul-lez- \\ Durance, France \\ ${ }^{2}$ Department of Biophysics, Centre of the \\ Region Haná for Biotechnological and \\ Agricultural Research, Faculty of Science, \\ Palacký University, Olomouc, Czech Republic \\ ${ }^{3}$ Institut des Biomolécules Max Mousseron \\ (IBMM), UMR 5247, CNRS, University of \\ Montpellier, Montpellier, France \\ Correspondence \\ Michel Havaux, Institute of Biosciences and \\ Biotechnologies, CEA/Cadarache, Aix \\ Marseille University, CEA, CNRS, BIAM, \\ UMR7265, F-13108 Saint-Paul-lez-Durance, \\ France. \\ Email: michel.havaux@cea.fr

\section{Present address} \\ Leonard Shumbe, Plant Genetics, TERRA \\ Teaching and Research Center, Gembloux \\ Agro-Bio Tech, University of Liège, Gembloux, \\ Belgium. \\ Funding information \\ Agence Nationale de la Recherche; ECCOREV; \\ European Union/Palacky University grant, \\ Grant/Award Number: \\ CZ.02.2.69/0.0/0.0/16_027/0008482; CEA \\ Radiobiology Program
}

\begin{abstract}
Lipid peroxidation is a primary event associated with oxidative stress in plants. This phenomenon secondarily generates bioactive and/or toxic compounds such as reactive carbonyl species (RCS), phytoprostanes, and phytofurans, as confirmed here in Arabidopsis plants exposed to photo-oxidative stress conditions. We analyzed the effects of exogenous applications of secondary lipid oxidation products on Arabidopsis plants by luminescence techniques. Oxidative damage to attached leaves was measured by autoluminescence imaging, using a highly sensitive CCD camera, and the activity of the detoxification pathway, dependent on the transcription regulator SCARECROW-LIKE 14 (SCL14), was monitored with a bioluminescent line expressing the firefly LUCIFERASE (LUC) gene under the control of the ALKENAL REDUCTASE (AER) gene promoter. We identified 4-hydroxynonenal (HNE), and to a lesser extent 4-hydroxyhexenal (HHE), as highly reactive compounds that are harmful to leaves and can trigger AER gene expression, contrary to other RCS (pentenal, hexenal) and to isoprostanoids. Although the levels of HNE and other RCS were enhanced in the SCL14-deficient mutant (scl14), exogenously applied HNE was similarly damaging to this mutant, its wild-type parent and a SCL14-overexpressing transgenic line (OE:SCL14). However, strongly boosting the SCL14 detoxification pathway and AER expression by a pre-treatment of OE:SCL14 with the signaling apocarotenoid $\beta$-cyclocitral canceled the damaging effects of HNE. Conversely, in the scl14 mutant, the effects of $\beta$-cyclocitral and HNE were additive, leading to enhanced leaf damage. These results indicate that the cellular detoxification pathway induced by the low-toxicity $\beta$-cyclocitral targets highly toxic compounds produced during lipid peroxidation, reminiscent of a safener-type mode of action.
\end{abstract}

\section{1 | INTRODUCTION}

In their pioneer work, Vavilin and Ducruet (1998) identified the origin of the high temperature thermoluminescence band $\mathrm{HT}_{2}$ emitted at

Abbreviations: $\beta$-CC, $\beta$-cyclocitral; ${ }^{1} \mathrm{O}_{2}$, singlet oxygen; AER, ALKENAL REDUCTASE; ALA, linolenic acid; HHE, 4-hydroxy hexenal; HNE, 4-hydroxynonenal; HOTE, hydroxyoctadecatrienoic acid; PFD, photon flux density; PhytoF, phytofurans; PhytoP, phytoprostanes; RCS, reactive carbonyl species; ROS, reactive oxygen species; SCL14, SCARECROW-LIKE 14; WT, wild type. around $130^{\circ} \mathrm{C}$ from chlorophyll-containing samples as the radiative breakdown of pre-existing lipid peroxides during the heating process. They proposed that the decomposition reaction leads to the formation of carbonyls in triplet state with following migration of excitation energy toward chlorophyll. Subsequently, the $\mathrm{HT}_{2}$ thermoluminescence band was used as an index of lipid peroxidation and oxidative stress in a number of studies on the responses of plants to environmental stresses (e.g. Havaux, 2003; Havaux et al., 2005; Repetto et al., 2015; Skotnica et al., 2003). Ducruet (2003) also pointed to the 
potential application of lipid peroxidation-related luminescence for imaging oxidative stress in whole leaves. Based on this idea, Havaux et al. (2006) devised a method for imaging the spontaneous luminescence emitted by whole plants pre-exposed to oxidative stress conditions using a highly sensitivity, low-noise cooled CCD (Charge Coupled Device) camera. Interestingly, the intensity of the signal imaged at room temperature was shown to be well correlated with the amplitude of the $\mathrm{HT}_{2}$ thermoluminescence band, suggesting a common origin (Havaux et al., 2006). The causal link between the autoluminescence signal imaged in plants and lipid oxidation was demonstrated using Arabidopsis mutants affected in lipid hydroperoxide metabolism and by comparing the characteristics of the in vivo signal with the luminescence signal emitted by oxidized lipid solutions (Birtic et al., 2011). Autoluminescence imaging has become a simple and sensitive non-invasive method to visualize and map patterns of lipid oxidation in plants (e.g. Beaugelin et al., 2019; D'Alessandro et al., 2018; Kobayashi et al., 2006; Levesque-Tremblay et al., 2009; Prasad \& Pospísil, 2013).

The decomposition of lipid peroxides leads to a variety of secondary compounds, some of which are toxic and damaging to living cells (Sousa et al., 2017). In particular, lipid peroxidation can generate reactive carbonyl species (RCS), which can readily react with biological molecules such as proteins and DNA (Mano et al., 2019; Wei \& Yin, 2015). Formation of lipid RCS can occur non-enzymatically, involving redox catalysts and reductants, or enzymatically, involving lipoxygenase and hydroperoxide lyase (Mano et al., 2019). Phytoprostanes (PhytoP) and phytofurans (PhytoF) are another type of secondary products of lipid oxidation. They are isoprostanoids derived non-enzymatically from the oxidation of linolenic acid (ALA) (Galano et al., 2017; Imbusch \& Mueller, 2000). Carbonyl compounds are electrophiles and can react with nucleophilic groups in biomolecules to make covalent bonds (Farmer \& Mueller, 2013). Typical reactions between RCS and amino acids in proteins are Schiff base formation and by Michael addition. However, it is difficult to generalize the mode of interaction between RCS and their target proteins because the reactivity depends on a variety of factors such as carbon chain length, number of unsaturated bonds, extent of oxygenation as well as polarity, hydrophobicity/hydrophilicity, solubility, and volatility. Typical RCS observed in plants under oxidative stress conditions are malondialdehyde, 4-hydroxynonenal (HNE), 4-hydroxyhexenal (HHE), and acrolein (Chan et al., 2012; Mano et al., 2010; Roach et al., 2017; Roach et al., 2018). Because of their high reactivity, those compounds can propagate oxidative stress within the cells and can ultimately lead to cell death. A recent genetic study has confirmed that lipid unsaturation is a key component in chloroplast-mediated cell death in Arabidopsis (Li et al., 2020). To protect themselves against the damaging effects of lipidic RCS, plants contain a panoply of detoxifying enzymes, including various reductases and dehydrogenases, that can convert RCS to less toxic chemical forms such as alcohols and carboxylic acids (Mano et al., 2019).

Recently, D'Alessandro et al. (2018) showed that the signaling apocarotenoid $\beta$-cyclocitral $(\beta-\mathrm{CC})$ can trigger a cellular detoxification mechanism controlled by TGAll transcription factors interacting with the SCARECROW-LIKE 14 (SCL14) transcription regulator. $\beta$-CC is produced under stress conditions by oxidation of $\beta$-carotene by singlet oxygen $\left({ }^{1} \mathrm{O}_{2}\right)$ in the PSII reaction centers (D'Alessandro \& Havaux, 2019; Ramel et al., 2012). Through the induction of several ANAC transcription factors (members of the NAC [NAM, ATAF and CUC] family), the TGAll/SCL14 complex governs the expression of detoxifying enzymes including short-chain dehydrogenases/reductases (SDRs), monooxygenases, 2-alkenal reductases (AERs), aldo-keto reductases (AKRs), aldehyde dehydrogenases (ALDH), and glucosyl and glutathione transferases, which target RCS. This enhancement of the detoxification capacities is likely to participate in the $\beta$-CCinduced tolerance of plants against pro-oxidative stress conditions, such as high light and drought (D'Alessandro et al., 2018; D'Alessandro et al., 2019; Ramel et al., 2012). The SCL14 knockout Arabidopsis mutant scl14 was unresponsive to $\beta$-CC and remained sensitive to photo-oxidative stress after exposure to $\beta$-CC, contrary to the wild type (D'Alessandro et al., 2018). Since a major source of toxic compounds during oxidative stress is lipid peroxidation, D'Alessandro et al. (2018) hypothesized that the protective effect of $\beta$-CC mainly acts on lipid oxidation products. This hypothesis is analyzed in the present study using autoluminescence imaging to monitor the toxicity of RCS in leaves. The damaging effects of lipid RCS and the mitigating effect of $\beta$-CC are investigated in Arabidopsis plants with different levels of the SCL14-dependent detoxification pathway.

\section{2 | MATERIALS AND METHODS}

\subsection{Plant material and stress treatments}

The experiments were performed on 4-week-old Arabidopsis plants (Arabidopsis thaliana L. Heynh). The following genotypes were used: the wild type (WT, ecotype Col-0), the scl14 knockout mutant, and a SCL14 overexpressor OE:SCL14, which have been described previously (D'Alessandro et al., 2018; Fode et al., 2008). Plants were grown under controlled environmental conditions in phytotrons of the Phytotec platform at CEA/Cadarache: photon flux density (PFD) of $120 \mu \mathrm{mol}$ photons $\mathrm{m}^{-2} \mathrm{~s}^{-1}$, 8-h photoperiod, day/night temperature of $20 / 18^{\circ} \mathrm{C}$. Photooxidative stress was imposed by transferring plants to a high PFD of $1500 \mu \mathrm{mol}$ photons $\mathrm{m}^{-2} \mathrm{~s}^{-1}$ and an air temperature of $7^{\circ} \mathrm{C}$ for $24 \mathrm{~h}$. Controlling air temperature ensures a leaf temperature of around $18^{\circ} \mathrm{C}$, thus avoiding heat stress during the high light treatment (Huang et al., 2019; Ramel et al., 2013).

Treatment of Arabidopsis plants with volatile $\beta$-CC was done in hermetically closed transparent plastic boxes, as previously described (Ramel et al., 2012). $100 \mu$ l of $\beta$-CC was deposited on a cotton ball in the center of the box, and plants were exposed to the $\beta$-CCcontaining atmosphere for $4 \mathrm{~h}$ in low light.

\section{2 | Lipid peroxidation}

Lipid peroxidation was measured by quantifying HOTEs (hydroxyoctadecatrienoic acids, $\mathrm{C} 18: 3-\mathrm{OH}$ ), oxidation products of 
linolenic acid (C18:3, n-3, ALA) (Ksas \& Havaux, 2020; Montillet et al., 2004). Lipids were extracted from leaf samples (ca. $300 \mathrm{mg}$ fresh weight) in methanol/chloroform, and HOTEs were quantified by HPLC-UV as detailed elsewhere (Ksas \& Havaux, 2020; Montillet et al., 2004).

\section{$2.3 \quad$ Lipidic RCS}

Hydroxyalkenals (4-hydroxynonenal HNE, 4-hydroxyhexenal HHE) and other RCS (trans-2-pentenal, trans-2-hexenal, hexanaldehyde) were quantified from $100 \mathrm{mg}$ fresh material by GC-MS/MS in the Functional Lipidomics Platform of INSA-Lyon, using the protocol detailed in Michalski et al. (2008). Authentic standards of the different compounds were used for the peak identifications and quantifications.

\section{4 | Phytoprostanes and phytofurans}

Phytoprostanes (PhytoP) and phytofurans (PhytoF) extraction was carried out as described elsewhere (Yonny et al., 2016), with some modifications. Around $200 \mathrm{mg}$ of frozen plant tissue was added in grinding matrix tubes (Lysing matrix D) with $25 \mu$ l of butylated hydroxytoluene (BHT, 1\% in water) and $1 \mathrm{ml}$ of methanol. The tubes were placed in a FastPrep-24 (MP Biochemicals), and the samples were ground for $30 \mathrm{~s}$ at a speed of $6.5 \mathrm{~m} \mathrm{~s}^{-1}$. Suspensions were transferred into $15-\mathrm{ml}$ centrifuge tube, and $1 \mathrm{ml}$ of methanol, $4 \mu \mathrm{l}$ of internal standard mixture (two home-made compounds, C19-16- $\mathrm{F}_{1 \mathrm{t}}-\mathrm{PhytoP}$, and $\mathrm{C} 21-15-\mathrm{F}_{2 \mathrm{t}}$-IsoP at the concentration of $1 \mathrm{ng} \mathrm{\mu l}^{-1}$ ), and $1.5 \mathrm{ml}$ of phosphate buffer $\left(50 \mathrm{mM}\right.$ pH 2.1, prepared with $\mathrm{NaH}_{2} \mathrm{PO}_{4}$ and $\mathrm{H}_{3} \mathrm{PO}_{4}$ ) saturated in $\mathrm{NaCl}$ was added. This mixture was stirred for $1 \mathrm{~h}$ at $20^{\circ} \mathrm{C}$. After centrifugation, the upper organic phase was separated and concentrated under a stream of nitrogen at $40^{\circ} \mathrm{C}$. Afterward, lipids were hydrolyzed with $950 \mu \mathrm{l}$ of $\mathrm{KOH}$ for $30 \mathrm{~min}$ at $40^{\circ} \mathrm{C}$. After incubation, $1 \mathrm{ml}$ of formic acid $(40 \mathrm{mM}, \mathrm{pH} 4.6)$ was added before running the SPE separation on Oasis MAX mixed polymer phase cartridges. Cartridges were conditioned with $2 \mathrm{ml}$ of methanol and equilibrated with $2 \mathrm{ml}$ of formic acid $(20 \mathrm{mM}, \mathrm{pH} 4.5)$. After loading the sample, successive washings were performed using $1.5 \mathrm{ml}$ of $\mathrm{NH}_{3} 2 \%$ (v/ v), $1.5 \mathrm{ml}$ of a mixture of formic acid (20 mM): methanol (70:30, $\mathrm{v} / \mathrm{v}$ ), and then $1.5 \mathrm{ml}$ of hexane. PhytoP and PhytoF retained were eluted with $1.5 \mathrm{ml}$ of hexane/ethanol/acetic acid (70:29.4:0.6). Finally, the sample was concentrated with $\mathrm{N}_{2}$ at $40^{\circ} \mathrm{C}$, and it was reconstituted in $100 \mu \mathrm{l}$ of mobile phase, transferred onto an Eppendorf centrifugal device $(0.45 \mu \mathrm{m}, 8500 \mathrm{~g}$ for $1 \mathrm{~min})$ before its injection in the micro-HPLC-QTRAP system.

Oxidized lipid products were analyzed according to the method previously reported (Vigor et al., 2018). Samples were separated on a HALO C-18 column $(0.5 \times 100 \mathrm{~mm}, 2.7 \mu \mathrm{m}$, Eksigent Technologies) using a micro liquid chromatography (Eksigent ${ }^{\circledR}$ MicroLC 200 plus; Eksigent Technologies) coupled to an ESI-QTrap mass spectrometer (SCIEX QTRAP 5500, Sciex Applied Biosystems). The mobile phase consisted of a binary gradient of solvent $A$ (water with $0.1 \%[\mathrm{v} / \mathrm{v}]$ of formic acid) and solvent B (ACN/methanol; 8:2, $\mathrm{v} / \mathrm{v}$; with $0.1 \%[\mathrm{v} / \mathrm{v}]$ of formic acid). The gradient elution program was performed as follows: $17 \%$ solvent $B$ at 0 min until $1.6 \mathrm{~min}$, then $21 \%$ solvent $B$ at $2.8 \mathrm{~min}, 25 \%$ solvent $B$ at $7.3 \mathrm{~min}, 28.5 \%$ solvent $B$ at $8.8 \mathrm{~min}, 33.1 \%$ solvent $B$ at $9.6 \mathrm{~min}, 33.3 \%$ solvent $B$ at $10.9 \mathrm{~min}, 40 \%$ solvent $B$ at $15 \mathrm{~min}$, and $95 \%$ solvent $B$ at $16.5 \mathrm{~min}$ for $2.5 \mathrm{~min}$, and then returned to the initial conditions. Five microliter of sample was injected and eluted at a flow rate of $0.03 \mathrm{ml} \mathrm{min}^{-1}$.

The ionization source was electrospray (ESI) in negative mode. Detection of the fragmentation ion products from each deprotonated molecule $[\mathrm{M}-\mathrm{H}]^{-}$was performed in the multiple reaction monitoring (MRM) mode with optimized conditions (ion optics and collision energy). Data processing was performed by MultiQuant 3.0 software (Sciex Applied Biosystems). The isoprostanoid quantifications were based on the analytes to internal standard ratio using the obtained calibration curves, which were calculated by the linear regression at least six concentrations of standards.

\section{$2.5 \quad$ Leaf treatments}

Droplets ( $5 \mu \mathrm{l}$ ) of RCS, $\beta$-CC, PhytoP, or PhytoF solutions were deposited on the adaxial surface of attached leaves. Plants were kept in low light (around $20 \mu \mathrm{mol}$ photons $\mathrm{m}^{-2} \mathrm{~s}^{-1}$ ) under a hood for $1 \mathrm{~h}$ before analyzes. Pure HHE, HNE, and isoprostanoids were synthesized following published procedure (Cuyamendous et al., 2015; Oger et al., 2008; Soulère et al., 2007). $\beta$-CC and pentenal were purchased from Sigma-Aldrich. Hexenal was obtained from Alfa Aesar. RCS and phytoprostanoids were used at a concentration of $0.2 \mathrm{mg} \mathrm{ml}^{-1} \cdot \beta-\mathrm{CC}$ was used at concentrations up to $30 \mathrm{mg} \mathrm{ml}^{-1}$.

\subsection{Luciferase lines}

Luciferase was used as a reporter of $A E R$ gene expression in Arabidopsis. A transgenic line $p A E R: L U C$ was generated to express the firefly luciferase LUC gene under the control of the AER promoter.

The $p A E R: L U C$ vector (AERpromoter-pBGWL7) was constructed by use of the gateway cloning technology as described in the manufacturer's protocol (Invitrogen). The AER promoter was obtained from A. thaliana Col-0 genomic DNA by PCR, using the primer pair AT5G16970GW-F and AT5G16970GW-R, containing attB flanking sequences at the respective $5^{\prime}$-ends. BP recombination between the attB flanking sites of the AER-promoter and the attP sites of the donor vector pDonor201 (Invitrogen) was used to generate the entry clone pDonor201-AERpromoter. The BP reaction was performed as described in the manufacturer's manual (Invitrogen) with some modifications: $35.1 \mathrm{ng}$ of the purified attB-AER promoter was mixed with $100 \mathrm{ng}$ of pDonor201 vector and $0.5 \mu \mathrm{l}$ of BP clonase II enzyme mix (Invitrogen) in a total volume of $2.5 \mu \mathrm{l}$. After $1 \mathrm{~h}$ of incubating the mixtures at $25^{\circ} \mathrm{C}, 1 \mu \mathrm{l}$ of proteinase $\mathrm{K}$ was added to stop the reaction and 
the samples were incubated at $37^{\circ} \mathrm{C}$ for $10 \mathrm{~min}$. Two microliter of the BP reaction was used to transform $50 \mu$ of One Shot TOP10 chemical competent cells (Invitrogen) by heat shock. A negative control BP reaction was performed as described for the $B P$ reaction, but without the attB-AER promoter fragment. Positive pDonor201-AERpromoter clones were identified from LB-Kanamycin $\left(50 \mu \mathrm{g} \mathrm{ml}^{-1}\right)$ plates by colony $\mathrm{PCR}$, using the pDonor- $\mathrm{F}$ and $\mathrm{pDonor}-\mathrm{R}$ primer pair and confirmed by sanger sequencing of Plasmids purified from positive colonies. LR recombination between the attL sites of the entry clone pDonor201-AERpromoter and the attR sites of the destination vector pBGWL7 (Karimi et al., 2005) was used to generate the expression vector AERpromoter-pBGWL7, thus placing the AER promoter directly upstream the Luciferase gene in the pBGWL7 plasmid. The LR reaction was carried out exactly as described in the manufacturer's protocol, making use of $100 \mathrm{ng}$ each of the entry clone and the destination vector. One microliter of LR reaction mix was used to transform $50 \mu$ l of One Shot TOP10 chemical competent cells (Invitrogen) by heat shock. Colony PCR with AT5G16970GW-F and HJ108-R primer pair was used to screen for positive colonies on LBspectinomycin $\left(50 \mu \mathrm{g} \mathrm{ml}^{-1}\right)$ plates. AERpromoter-pBGWL7 plasmid was extracted from a positive colony and $100 \mathrm{ng}$ of the plasmid was used to transform $50 \mu \mathrm{l}$ of GV3101 Agrobacterium electrocompetent cells. Transformed agroclones growing on LB-Rif/Spectinomycin (50 $\mu \mathrm{g} \mathrm{ml}^{-1}$ each) plates were again confirmed by colony PCR. The primer sequences are given in Supplementary Table S1.

\section{7 | (Auto)luminescence imaging}

A liquid nitrogen-cooled CCD camera (VersArray 1300B; Roper Scientific) was used to image the ultraweak luminescence associated with oxidative stress and lipid peroxidation in plants, as previously described (Birtic et al., 2011). The back-illuminated CCD (CCD36-40; e2v Technologies) with a $1340 \times 1300$ imaging array operates at a temperature of $-110^{\circ} \mathrm{C}$. The sample was imaged on the sensor by a $50-\mathrm{mm}$ focal distance lens with an f-number of 1.2 (F mount Nikkor 50-mm, f:1.2; Nikon) equipped with a shutter. Acquisition time was 20 min (unless specified otherwise), and on-CCD binning of $2 \times 2$ was used to increase detection sensitivity, so that the resulting resolution was $650^{\prime} 670$ pixels. Plants were dark-adapted for $2 \mathrm{~h}$ before measuring autoluminescence. Considering that plants were treated with RCS for $1 \mathrm{~h}$ in low light (see above, "leaf treatments" paragraph), the images were recorded $3 \mathrm{~h}$ after application of RCS droplets on the leaves.

For spectral analysis of the signal, bandpass filters with a bandwidth of $50 \mathrm{~nm}$ (Omega Optical, 425-, 475-, 525-, 575, 625-, 675-, 725-, 775-, 825-BP50 filters, diameter $4.6 \mathrm{~cm}$ ) were placed in front of the lens system of the camera. Pixel binning of $5 \times 5$ and acquisition time of $5 \mathrm{~min}$ were used for the image recordings. The bandpass of the optical filters has very sharp edges $(<10 \mathrm{~nm}$ from 0 to maximum transmission) and a high \% transmission (> 90\%).

The same imaging system was used for recording the luciferin/ luciferase luminescence from the $p A E R: L U C$ line. Plants were sprayed with a $5 \mathrm{mM}$ aqueous solution of luciferin containing $0.01 \%$ Triton
100. Acquisition time was $1 \mathrm{~min}$ and the on-CCD pixel binning was $2 \times 2$.

Images were saved in color using the color palette of the camera software (WinView) and subsequently analyzed using Image J software.

\section{3 | RESULTS}

\section{1 | Primary and secondary products of lipid peroxidation in Arabidopsis leaves}

WT Arabidopsis plants were exposed to high light $(1500 \mu \mathrm{mol}$ photons $\left.\mathrm{m}^{-2} \mathrm{~s}^{-1}\right)$ under controlled air temperature $\left(7^{\circ} \mathrm{C}\right)$, leading to photooxidative damage that can be visualized by leaf bleaching and shrinkage in Figure 1A. Controlling temperature avoids that the light stress treatment combines with heat stress (Huang et al., 2019; Ramel et al., 2013). The visual symptoms of leaf damage were associated with lipid peroxidation as revealed by autoluminescence imaging of lipid peroxides (Figure 1B). The latter technique measures the slow spontaneous decomposition of lipid peroxides present in the sample, which is accompanied by the formation of luminescent compounds such as triplet carbonyls and singlet oxygen $\left({ }^{1} \mathrm{O}_{2}\right)$ (Duran \& Cadenas, 1987; Havaux et al., 2006). The intensity of this luminescence emission has been previously correlated with the extent of lipid peroxidation measured by biochemical methods (Birtic et al., 2011; D'Alessandro et al., 2018; Johnson et al., 2007; LevesqueTremblay et al., 2009; Ramel et al., 2013). This signal and more generally the accumulation of hydroxy fatty acids and lipid peroxides have also been previously shown to be associated with the onset of programmed cell death in plant leaves (Beaugelin et al., 2019, 2020). Figure $1 \mathrm{C}$ shows the quantification of hydroxyoctadecatrienoic acids (HOTEs), which are hydroxy fatty acids resulting from oxidation of ALA, the major fatty acid in Arabidopsis. The HOTE levels markedly increased with high light stress (ca. 10-folds), indicating enhanced lipid peroxidation, in line with the increased intensity of leaf autoluminescence (Figure 1B).

Lipid peroxidation in high light-stressed Arabidopsis leaves was accompanied by the accumulation of secondary lipid oxidation products such as reactive carbonyl species RCS, PhytoP, and PhytoF (see chemical structures in Figure 2). There was a general tendency for RCS to accumulate after high light stress, and the increased concentration was significatively different from the control levels for HNE, HHE and hexenal (Figure 1D). The same phenomenon was observed for a number of PhytoP and PhytoF (Figure 1E). All PhytoF quantified in this study and several PhytoP (PP2, PP4, PP4, PP7, and PP8 in Figure $1 \mathrm{E}$ ) significantly increased in high light-treated leaves.

\subsection{RCS induce cell damage and trigger cellular detoxification}

We tested the damaging effects of representatives of secondary lipid oxidation products found in Arabidopsis leaves. Droplets of RCS and isoprostanoids were deposited on attached Arabidopsis leaves, and 

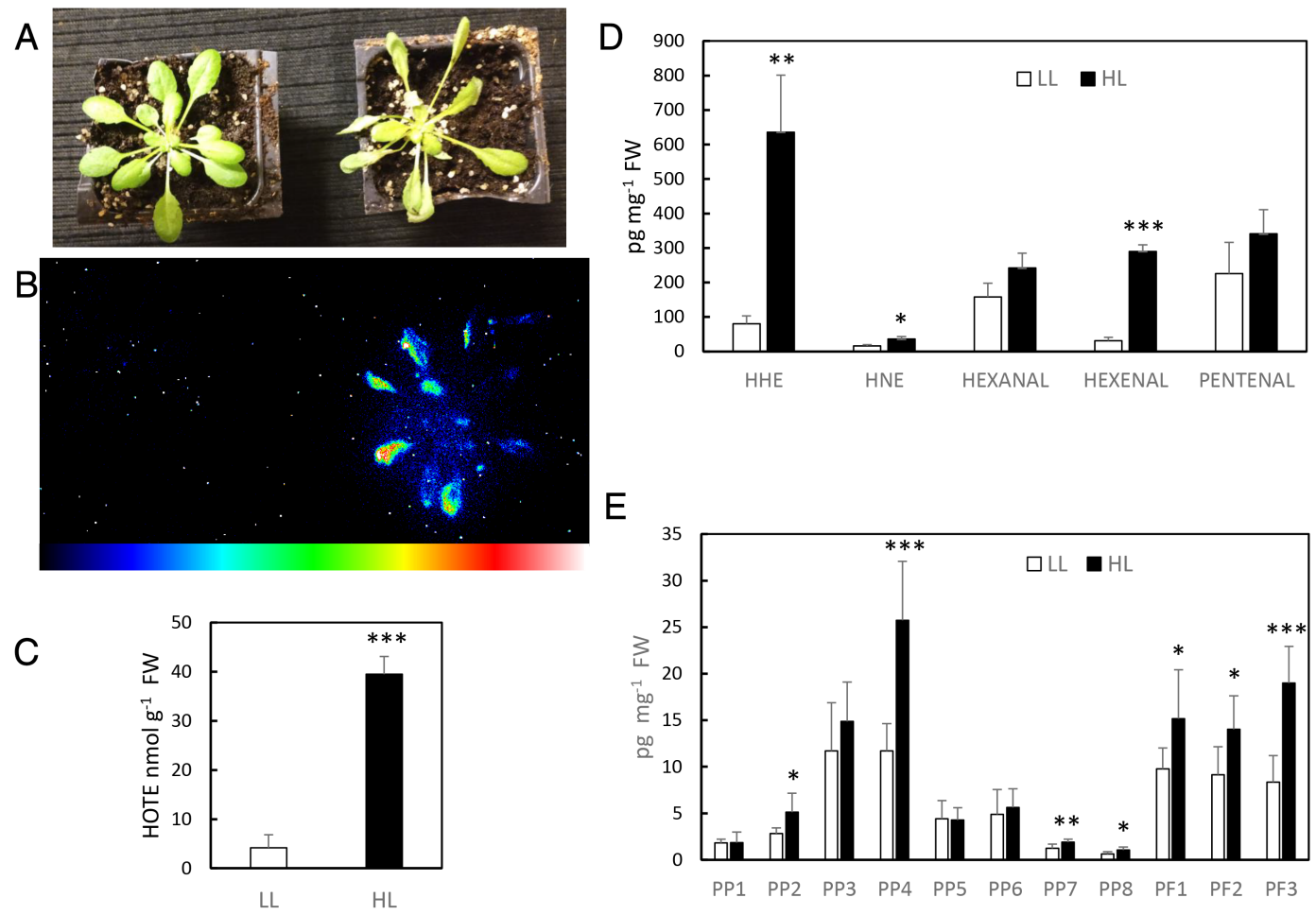

FIGURE 1 Lipid peroxidation in 4-week-old Arabidopsis plants exposed to photooxidative stress conditions. Plants were exposed to high light $\left(1500 \mu \mathrm{mol}\right.$ photons $\left.\mathrm{m}^{-2} \mathrm{~s}^{-1}\right)$ at low air temperature $\left(7^{\circ} \mathrm{C}\right)$ for $24 \mathrm{~h}$. (A) Picture of the plants before and after light stress. Control conditions before stress: $120 \mu \mathrm{mol}$ photons $\mathrm{m}^{-2} \mathrm{~s}^{-1}$ at $20^{\circ} \mathrm{C}$. (B) Autoluminescence imaging of lipid peroxides. The color palette indicates luminescence intensity from low (dark blue) to high (white) levels. (C) hydroxyoctadecatrienoic acid (HOTE) levels. (D) reactive carbonyl species (RCS) levels. (E) Phytoprostane (PP)/

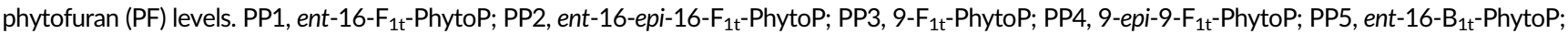
PP6, ent-9- $\mathrm{L}_{1 \mathrm{t}}-\mathrm{PhytoP}$; PP7, ent-9-epi-9- $\mathrm{D}_{1 \mathrm{t}}-\mathrm{PhytoP}$; PP8, ent-9- $\mathrm{D}_{1 \mathrm{t}}-\mathrm{PhytoP}$; PF1, ent-16(RS)-9-epi-ST- $\Delta^{14}-10-\mathrm{PhytoF}$; PF2, ent-9(RS)-12-epi-ST- $\Delta^{10}$ 13-PhytoF; PF3, ent-16(RS)-13-epi-ST- $\Delta^{14}$-9-PhytoF. ${ }^{*},{ }^{* *},{ }^{* * *}$, different from LL conditions at $P<0.05,0.01$ and 0.001 , respectively (Student's $t$-test)

FIGURE 2 Structure of lipid oxidation products used in this study: 4-HHE, 4-HNE, Trans-2 Hexenal, Trans-2-pentenal, 9-epi9- $\mathrm{F}_{1 \mathrm{t}}$-PhytoP (PP4 in Figure 1), and ent-9(RS)-12-epi-ST- $\Delta^{10}$. 13-PhytoF (PF2 in Figure 1)

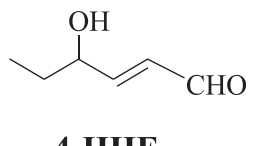

4-HHE<smiles>CC/C=C/C=O</smiles>

Pentenal<smiles>CCC1C(O)C[C@@H](O)[C@@H]1/C=C/C(O)CCCCCCCC(=O)O</smiles><smiles>CCCCCC(O)/C=C/C=O</smiles>

4-HNE<smiles>CCCC=CC=O</smiles>

Hexenal

ent-9-(RS)-12-epi-ST- $\Delta^{10}-13-P h y t o F$

the oxidative damage was monitored by autoluminescence imaging. Application of HNE resulted in luminescent spots, indicating oxidative damage and accumulation of lipid peroxides (Figures $3 \mathrm{~A}$ and S1). A similar treatment with $\mathrm{HHE}$ also induced luminescent spots, but their intensities were much weaker (Figure S1), in line with the lower toxicity reported for this hydroxyalkenal compared to HNE (Choudhary et al., 2005; Pohl \& Jovanovic, 2019). In contrast, pentenal or hexenal droplets appeared to be much less toxic than HNE/HHE since they 
did not induce luminescence at the same concentration (Figures $2 \mathrm{~B}$ and S1). Similarly, none of the PhytoP and PhytoF tested were able to induce a luminescence signal (Figures $3 \mathrm{C}$ and $\mathrm{S} 1$ ).

We analyzed the time course of the luminescence emission induced by HHE and HNE (Figure S2A). Technical reasons preclude the analysis of the first $3 \mathrm{~h}$ after application of the products: the applied RCS droplets were let to penetrate and dry out at the leaf surface for $1 \mathrm{~h}$, and the plants were subsequently dark-adapted for $2 \mathrm{~h}$ in the imaging system to eliminate the chlorophyll luminescence signal (Birtic et al., 2011). Consequently, the first image was recorded with a delay of $180 \mathrm{~min}$. HNE-induced leaf luminescence was found to fade away over time. The same phenomenon was observed with HHE.

We performed a spectral analysis of the HNE-induced leaf luminescence (Figure 3D). The luminescence spots were found to occur in the red region of the visible spectrum, peaking at around $725 \mathrm{~nm}$. No luminescence was detected below $600 \mathrm{~nm}$. This spectrum corresponds to previous spectra of leaf autoluminescence induced by oxidative stress (e.g. Birtic et al., 2011).

The low toxicity of PhytoP and PhytoF is also reflected by their incapacity to activate the detoxification pathway. Activity of the SCL14-dependent detoxification pathway was monitored with the help of the bioluminescent $p A E R: L U C$ line, in which the luciferase reporter gene was expressed under the control of the promoter of the $A E R$ gene, previously shown to be an essential player in the detoxification pathway (D'Alessandro et al., 2018; Fode et al., 2008). pAER: LUC line displayed a high luminescence signal when treated with HNE, indicating activation of the RCS-detoxifying enzyme AER (Figure 4E). The HNE-induced AER expression was confirmed by qRT-PCR analyzes (Figure S3). AER is a downstream gene in the SCL14-dependent detoxification response (D'Alessandro et al., 2018). Under photooxidative stress conditions, the sequential activation of genes encoding several ANAC transcription factors leads to the induction of detoxifying enzymes such AER or SDR1 (D'Alessandro et al., 2018). As shown in Supplemental Figure S3, HNE also induced the expression of ANAC102 and SDR1. Moreover, the HNE treatment strongly upregulated OXIDATIVE STRESS INDUCIBLE 1 (OXI1), the gene coding for the OXI1 kinase required for ${ }^{1} \mathrm{O}_{2}$-induced cell death (Shumbe et al., 2016).

Similarly to HNE, HHE induced luciferase/luciferin luminescence in the pAER:LUC line, though with a slightly lower intensity (Figure S4). Exposing plants to high light also led to an induction of AER expression (Figure $4 \mathrm{~F}$ ) in parallel with the accumulation of RCS (Figure 1D). This effect was not observed with PhytoP and PhytoF: the luminescence emission remains low at the control levels (Figure 4B-D).

\section{3 | RCS levels are increased in the SCL14- deficient scl14 mutant}

RCS and PhytoP/PhytoF were measured in leaves of the scl14 mutant, the SCL14-overexpressing line OE:SCL14 and their wild type (Figure 5). No difference was observed between the three genotypes for the isoprostanoids (Figure 5B). In contrast, leaves of the scl14 mutant exhibited moderate but significantly higher levels of HNE, HHE and hexenal compared to WT and OE:SCL14 leaves (Figure 5A).

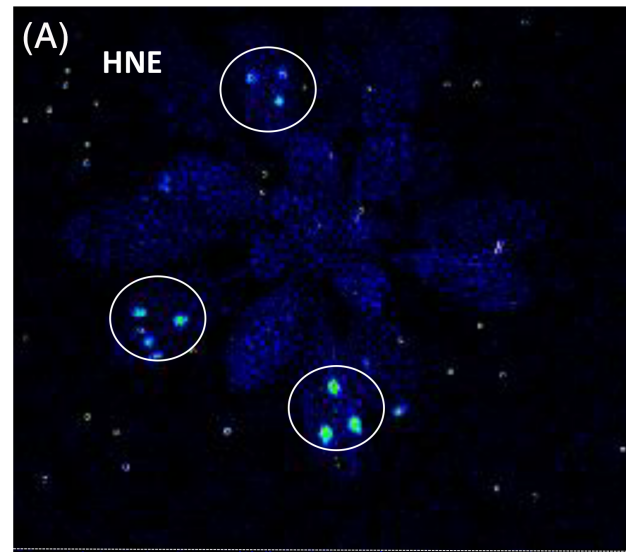

(C)

\section{PP4}

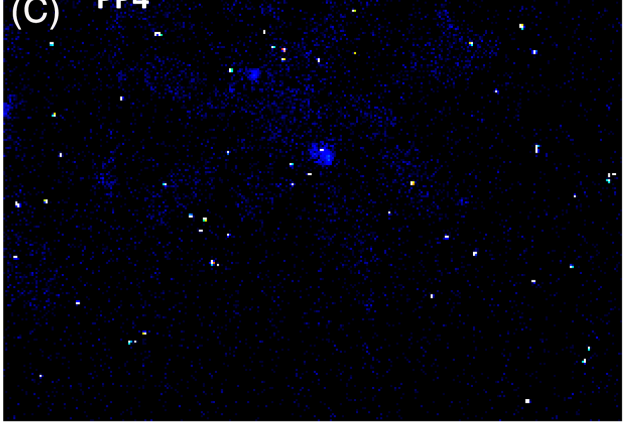

(B)

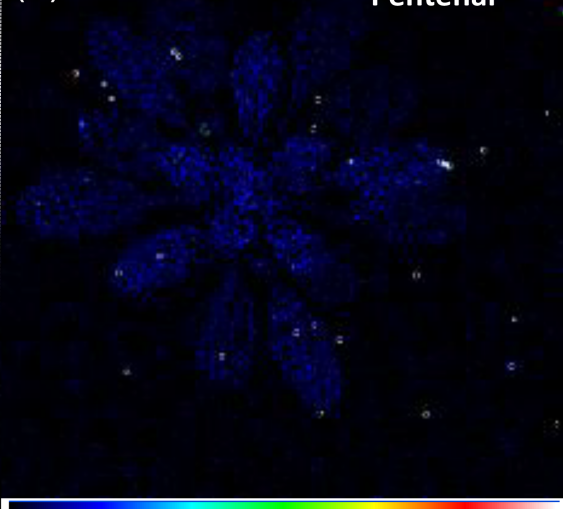

(D)

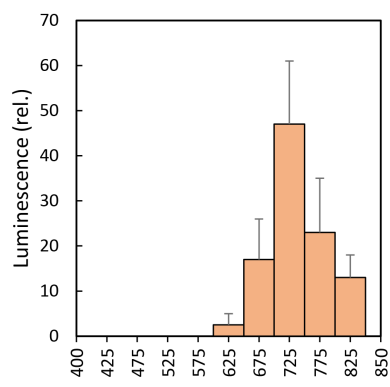

FIGURE 3 Luminescence spots induced in leaves of 4-week-old Arabidopsis plants by droplets $(5 \mu \mathrm{l})$ of (A) HNE, (B) Pentenal, (C) PP4. For HNE and Pentenal, three droplets were deposited on three different leaves. For PP4, two droplets were deposited on five different leaves. See legend of Figure 1 for the chemical name of PP4. Plants were kept in low light $(20 \mu \mathrm{mol}$ photons $\mathrm{m}^{-2} \mathrm{~s}^{-1}$ ) during the treatment.

(D) Spectrum of the HNE-induced luminescent spots 


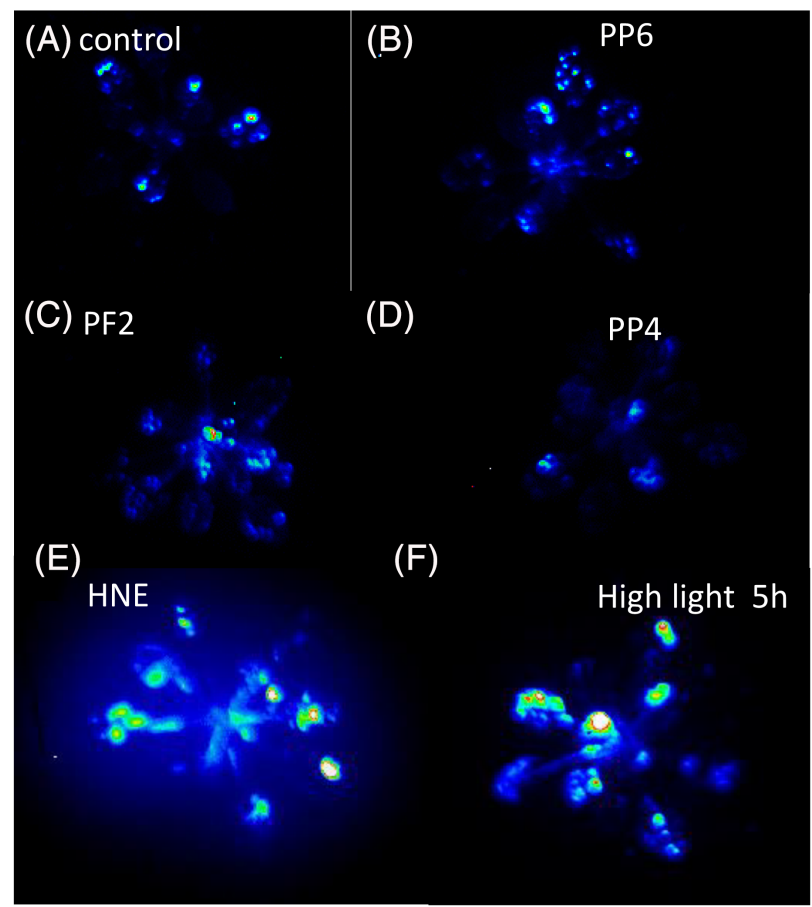

FIGURE 4 Induction of luciferase/luciferin luminescence in the pAER:LUC line exposed to (B) PP6, (C) PF2, (D) PP4, (E) HNE. Droplets of $5 \mu$ l were deposited on leaves of 4-week-old Arabidopsis plants. Plants were kept in low light $\left(20 \mu \mathrm{mol}\right.$ photons $\left.\mathrm{m}^{-2} \mathrm{~s}^{-1}\right)$ during the treatment. (A) Control, untreated plants. (F) Effect of high light stress $\left(1500 \mu \mathrm{mol} \mathrm{m} \mathrm{m}^{-2} \mathrm{~s}^{-1}\right.$ at $7^{\circ} \mathrm{C}$ for $\left.6 \mathrm{~h}\right)$. See legend of Figure 1 for the chemical name of PP4, PP6, and PF2

The three genotypes did not differ regarding the hexanal and pentenal levels.

\section{4 | HNE-induced cell death in Arabidopsis leaves with different SCL14 and AER levels}

HNE droplets were deposited on attached leaves of WT, scl14 and OE:SCL14 plants, leading to luminescent spots. The intensity of this luminescence did not differ between the three genotypes (Figure 6). This could be due to the high toxicity of HNE, which could overwhelm the capacities of the detoxification mechanisms when applied exogenously. This is consistent with the observation that the expression of the SCL14-dependent detoxification pathway is rather low under control light conditions $\left(120 \mu \mathrm{mol}\right.$ photons $\left.\mathrm{m}^{-2} \mathrm{~s}^{-1}\right)$, even in the SCL14 overexpressor (D'Alessandro et al., 2018). Compared to WT, AER gene expression was reduced by $20 \%$ in $\mathrm{scl} 14$ and was increased by $70 \%$ in OE:SCL14 (Figure S5A). Nevertheless, we noticed that the decrease in HNE-induced luminescence over time was slightly faster in WT than in scl14, leading to an almost doubling of the luminescence in scl14 relative to WT when the measurements were performed $6 \mathrm{~h}$ after HNE application (Figure S2B). This suggests a differential metabolization of HNE between the two genotypes in favor of WT.
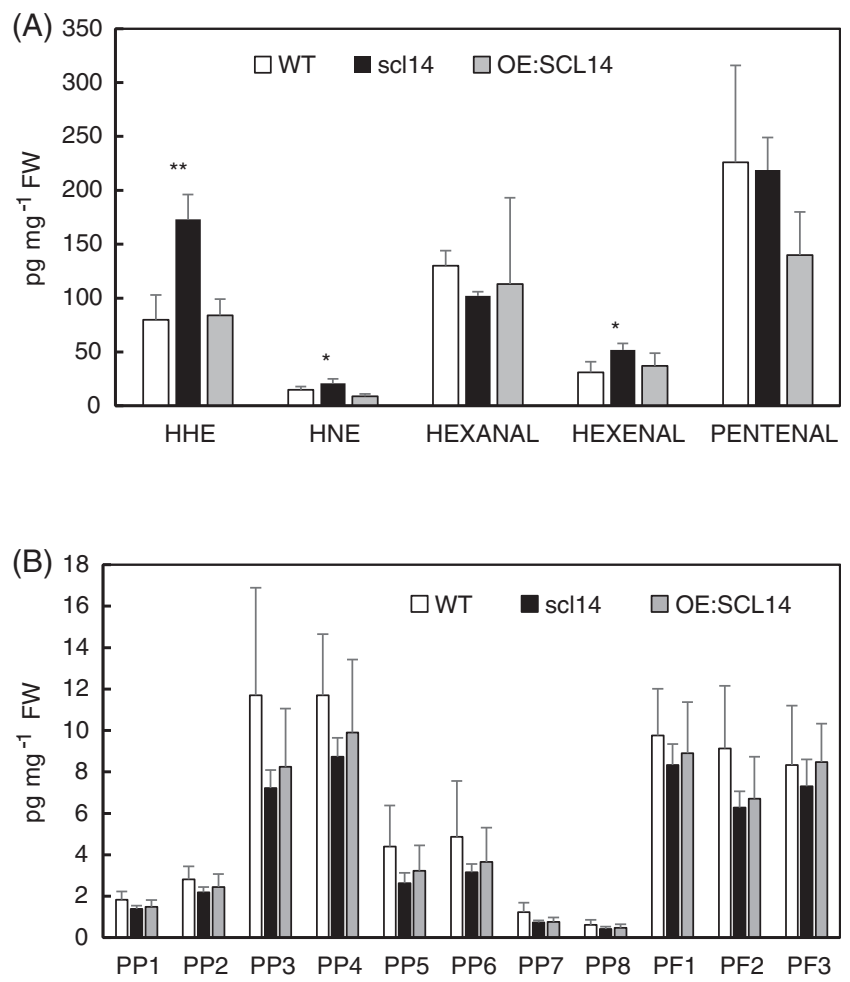

FIG URE 5 (A) Reactive carbonyl species (RCS) and (B) PhytoP (PP)/ PhytoF (PF) levels in 4-week-old WT Arabidopsis leaves and in leaves of scl14 knockout mutant and SCL4 overexpressor OE:SCL14. *, **, different from WT at $P<0.05$ and 0.01 , respectively (Student's $t$-test). See legend of Figure 1 for the chemical name of the PP and PF molecules

The xenobiotic detoxification pathway can be markedly upregulated by the signaling apocarotenoid $\beta-C C$, particularly in OE: SCL14 (D'Alessandro et al., 2018; Havaux, 2020). Exposure of OE: SCL14 plants to $\beta$-CC noticeably increased AER expression by a factor of 20 compared to control conditions, while expression levels were multiplied by a factor of 6 and 1.3 in WT and scl14, respectively (Figure S5C). Thus, AER expression in $\beta$-CC-treated leaves exhibited a 36-fold increase compared to AER expression in untreated WT leaves $\left(1.7^{\prime} 21\right.$, Figure S5A,C). Using pAER:LUC plants, Figures 7 and S5B confirm that $\beta$-CC activates the AER gene. However, based on the intensity of the luciferase/luciferin luminescence in Figure 7, $\beta$-CCinduced AER expression was lower than the HNE-induced upregulation.

Figure $8 \mathrm{~A}$ confirms the similar induction of lipid oxidation by HNE in the three genotypes. However, after 4-h exposure of whole plants to volatile $\beta$-CC, the HNE-induced luminescence was noticeably reduced in OE:SCL14 plants compared to untreated plants (Figure 8B). This phenomenon was not observed in WT and scl14. Thus, the marked induction of the detoxification capacities in $\beta$-CCtreated OE:SCL14 plants resulted in a substantial reduction of oxidative damage induced by high HNE concentrations. The $\beta$-CC effect on the SCL14-dependent pathway in WT and, a fortiori in scl14, does not appear to be sufficient to counteract the detrimental action of HNE. 


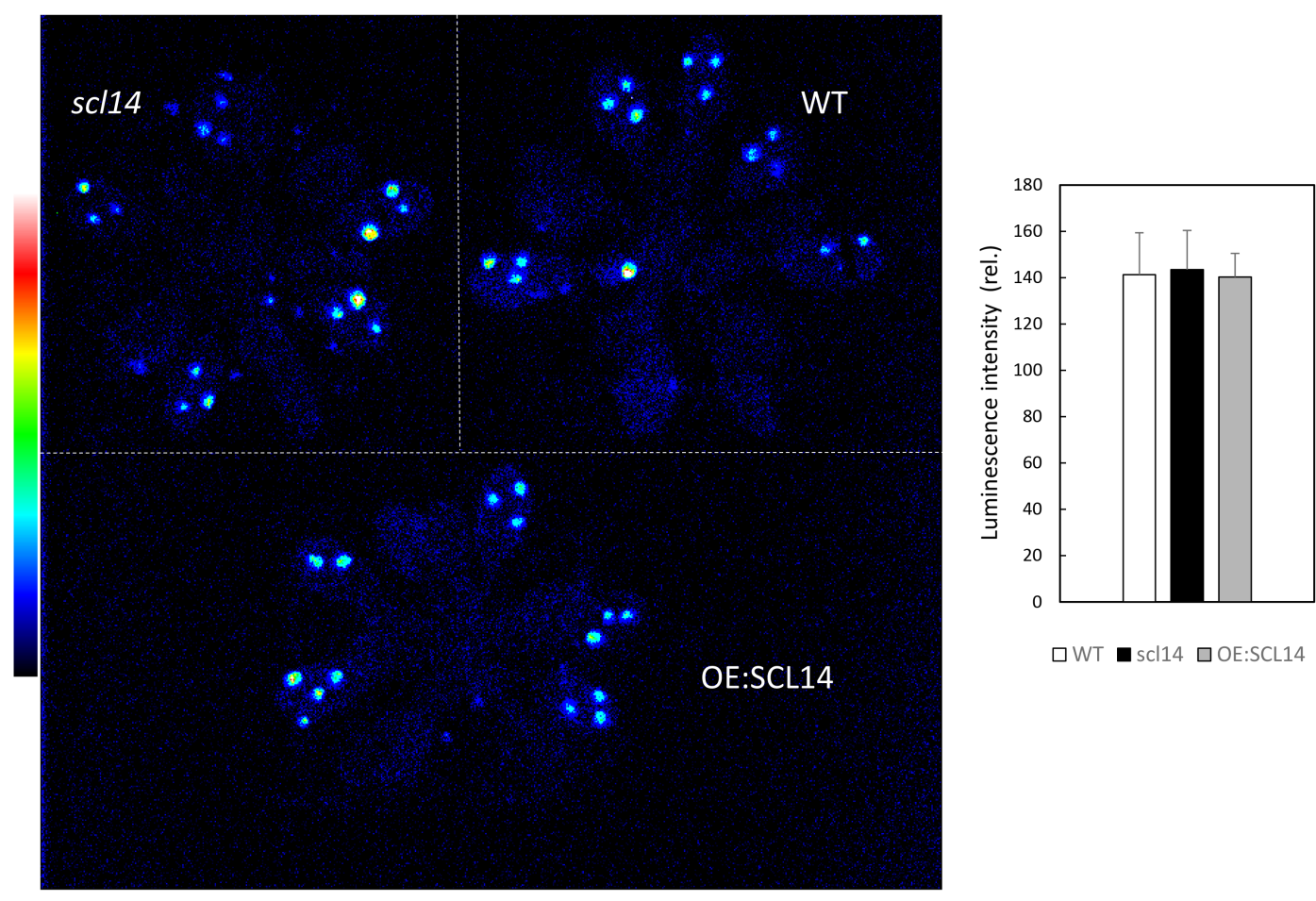

FIGURE 6 Luminescent spots induced in leaves of 4-week-old WT, scl14, and SCL14oex Arabidopsis plants by droplets of HNE. On the right, quantification of the luminescence intensity. Plants were kept in low light $\left(20 \mu \mathrm{mol}\right.$ photons $\left.\mathrm{m}^{-2} \mathrm{~s}^{-1}\right)$ during the treatment

Control
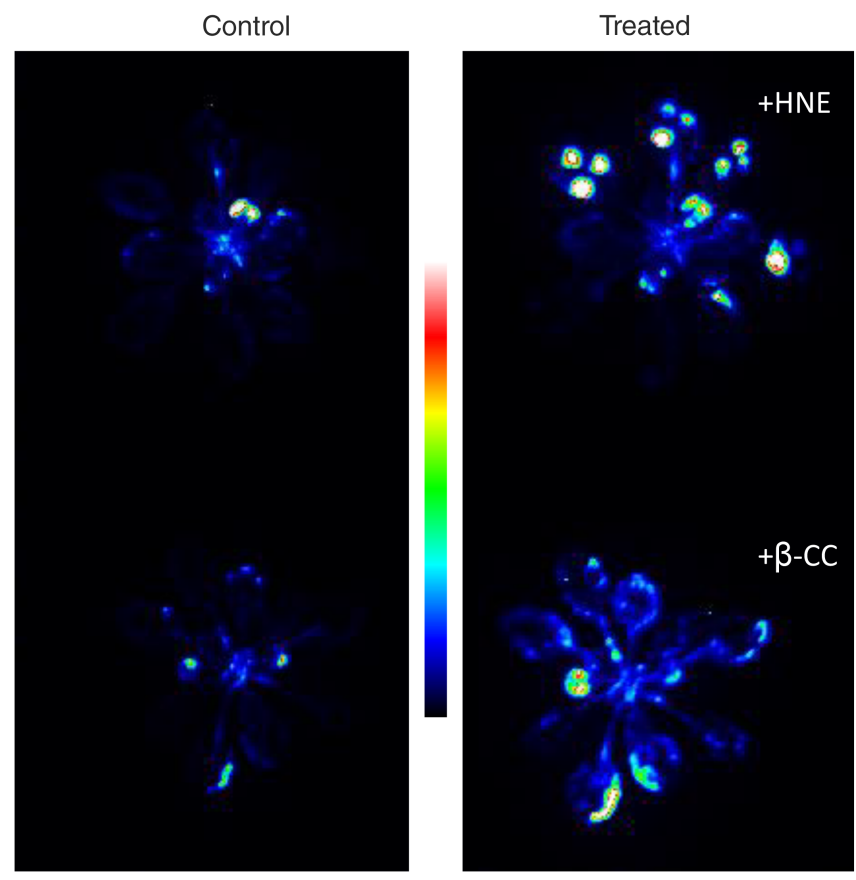

FIGURE 7 Induction of luciferase/luciferin luminescence in the pAER:LUC line by $\beta$-CC or HNE. The plants aged 4 weeks were kept in low light $\left(20 \mu \mathrm{mol}\right.$ photons $\left.\mathrm{m}^{-2} \mathrm{~s}^{-1}\right)$ during the treatment

To access the capacity of the SCL14 detoxification pathway against the combined effect of $\beta-C C$ and HNE, droplets of $\beta-C C$ and HNE were applied directly on leaves of scl14 mutant and OE:SCL14 lines either separately or combined in a respective sequential order.
$\beta-C C$ alone induced only a low luminescence in both scl14 and OE: SCL14 (Figure 9C). Even a 100-fold increase in $\beta$-CC concentration (from 0.3 to $30 \mathrm{mg} \mathrm{ml}^{-1}$ ) led to less damage than HNE. In the scl14 mutant, the application of $\beta-\mathrm{CC}$ before the HNE treatment resulted in a strongly increased luminescence intensity (Figure 9B) compared to treatment with a single compound (Figure 9A,C). This suggests an additive effect of $\mathrm{HNE}$ and $\beta-\mathrm{CC}$ on leaf oxidative injuries when the cellular detoxification efficiency is low. In striking contrast, the overexpressor exhibited a strongly attenuated luminescence signal when treated with $\beta-C C$ and HNE. Thus, priming cellular detoxification by $\beta$-CC application reduced leaf oxidative damage by HNE.

In Figure 10, we confirm that the intensity of the HNE-induced luminescent spots declined over time, with the luminescence measured $24 \mathrm{~h}$ after application of the compound being much weaker than the luminescence measured at time $3 \mathrm{~h}$. Conversely, the visual symptoms of damage increased over time. Thus, luminescence appeared to be an early phenomenon in the HNE-induced leaf damage. This is consistent with previous observations showing that lipid peroxidation is an early event in animal or plant tissue necrosis (Dalal \& Khanna-Chopra, 1999; Repetto et al., 2010).

\section{DISCUSSION}

Lipids of plant leaves are highly unsaturated (Douce \& Joyard, 1980) and are therefore very sensitive to oxidation (Bour et al., 2019). The major fatty acids in leaves are the polyunsaturated fatty acids ALA and linoleic acid (C18:2, n-6), with the former one 
FIGURE 8 Effect of pre-exposure of WT, scl14, and OE:SCL14 Arabidopsis plants (aged 4 weeks) to volatile $\beta$-CC (4-h exposure) on the luminescence induced by droplets of HNE. Plants were kept in low light $(20 \mu \mathrm{mol}$ photons $\mathrm{m}^{-2} \mathrm{~s}^{-1}$ ) during the treatments.

(A) Control plants. (B) $\beta$-CC treated plants.

(C) Quantification of luminescence intensity. ${ }^{* * *}$, different from control at $P<0.001$ (Student's $t$-test)
(A) Control

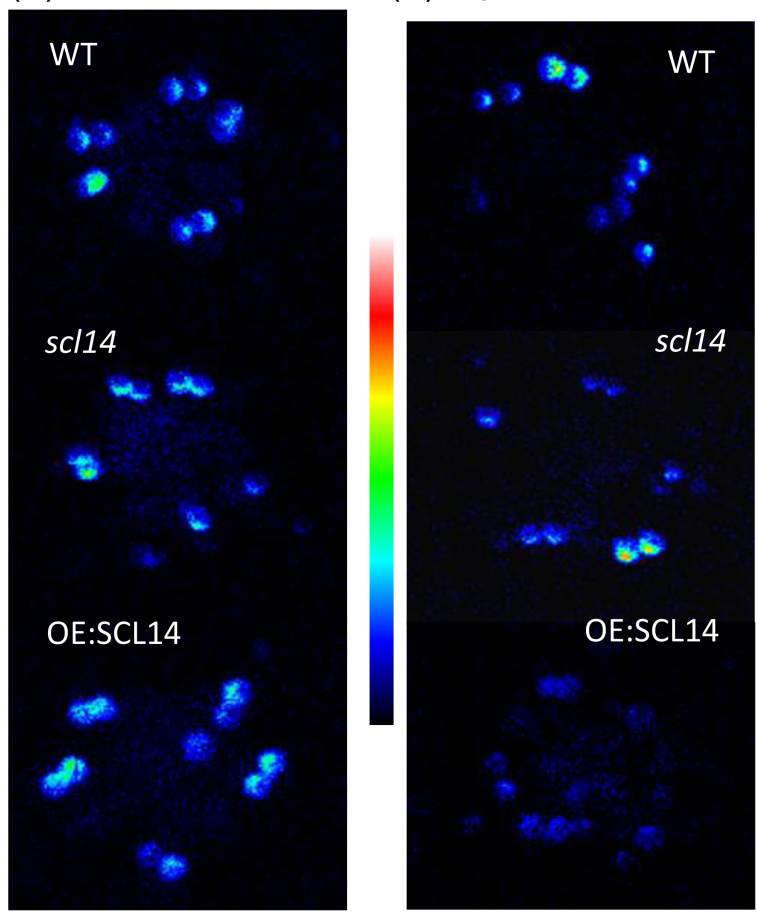

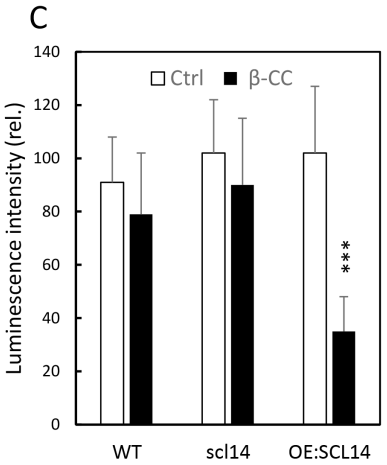

(A)

scl14

OE:SCL14

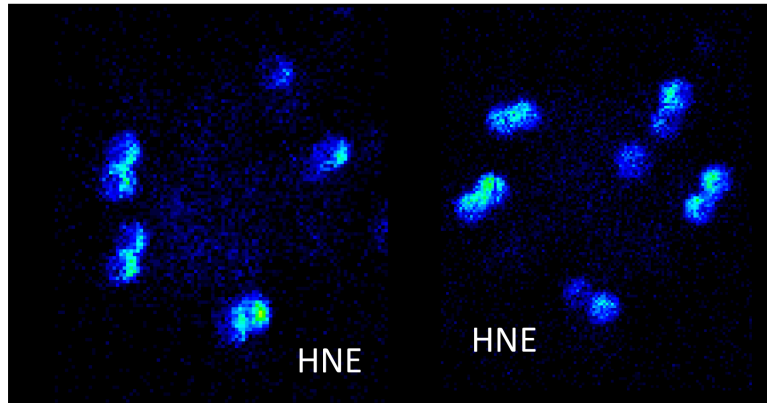

(B)

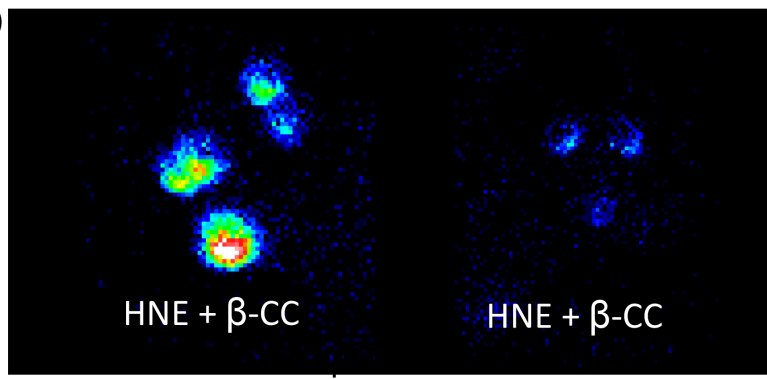

(C)

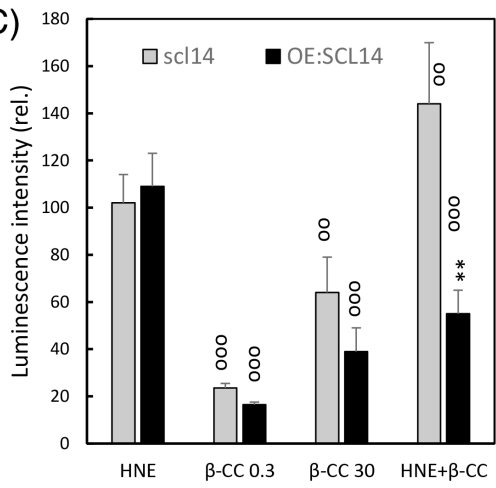

FIGURE 9 Luminescence spots induced in leaves of 4-week-old scl14 and OE:SCL14 plants by droplets of $\beta$-CC, HNE, and $\beta$-CC+HNE. (A) HNE treatment. (B) $\beta-C C+H N E$ treatment. $\beta-C C$ was applied prior to the HNE application. Plants were kept in low light $\left(20 \mu \mathrm{mol}\right.$ photons $\left.\mathrm{m}^{-2} \mathrm{~s}^{-1}\right)$ during the treatments. (C) Quantification of luminescence intensity induced by HNE, $\beta-\mathrm{CC}$ ( 2 concentrations) and $\beta-\mathrm{CC}+\mathrm{HNE}$. ${ }^{* *}$, different from sc14 at $P<0.01$; oo and ooo, different from HNE at $P<0.01$ and 0.001 , respectively (Student's $t$-test)

representing up to $50 \%$ of the total fatty acid content (Li-Beisson et al., 2013). The situation is even more extreme in thylakoids, a primary site of ROS photoproduction, where the ratio of unsaturated to saturated lipids is 9.4 to 1 , and ALA corresponds to $70 \%$ of the fatty acid content (Mano et al., 2019). Consequently, lipid peroxidation is usually a primary event associated with ROS production and oxidative stress in plants, leading to the accumulation of lipid peroxides and hydroperoxides (Birtic et al., 2011). 
(A)

HNE $3 \mathrm{~h}$

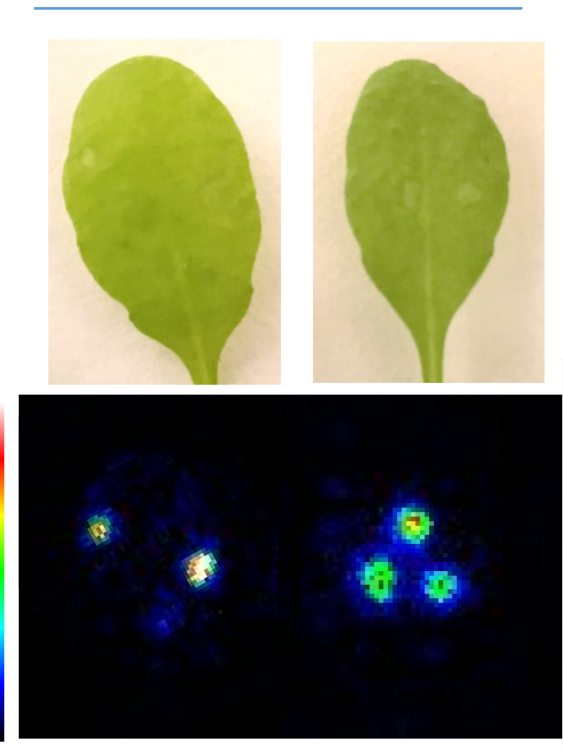

(B)

HNE $24 \mathrm{~h}$

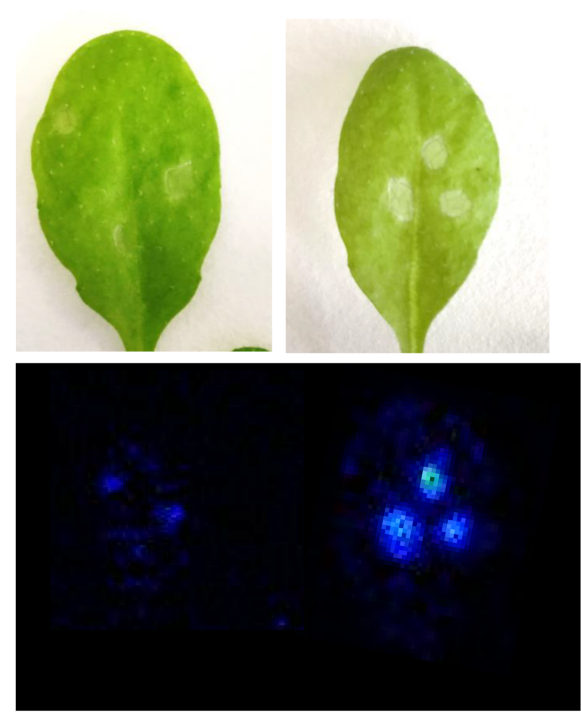

FIGURE 10 Attached Arabidopsis leaves (WT) treated with 5 - $\mu$ d droplets of HNE.

(A) Pictures and autoluminescence images taken $3 \mathrm{~h}$ after HNE application.

(B) Pictures and autoluminescence images taken $24 \mathrm{~h}$ after HNE application. At the bottom: quantification of the luminescence intensity. ${ }^{*}$, different at $P<0.01$ (Student's $t$-test)

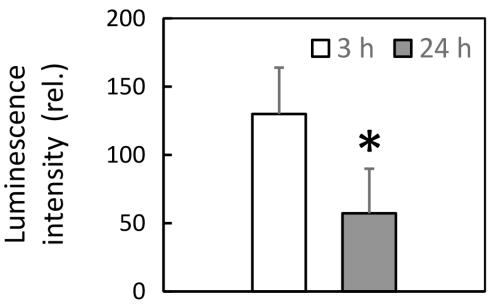

As shown here in photo-oxidized Arabidopsis leaves (Figure 1), these primary products of lipid peroxidation subsequently break down in a variety of secondary products such as RCS and isoprostanoids.

In the present study, some of the RCS, especially HNE and, to a lesser extent $\mathrm{HHE}$, were found to be very reactive and toxic to leaves, propagating oxidative degradations, whereas pentenal and hexenal had very little damaging effects at the same concentrations. This differential reactivity is in line with previous investigations on animal and plant cells showing a higher toxicity for HNE compared to HHE or hexenal (Biswas \& Mano, 2015; Choudhary et al., 2005; Pohl \& Jovanovic, 2019). However, several factors can influence the interaction of RCS with leaf tissues, such as their polarity, solubility, or volatility, which can modulate their apparent toxicity. Moreover, because of their reactivity, the applied HNE molecules are likely to affect only the upper cell layers of the leaves. Accordingly, chlorophyll fluorescence imaging showed that PSII photochemistry (Fv/Fm) was affected only at the site of application of the product, indicating no diffusion through the leaf tissue (Figure S6).

Because of their structural analogy to mammalian oxylipins derived from arachidonic acid, such as isoprostanes and prostaglandins, on which have been demonstrated a number of biological actions, PhytoP have been suggested to be capable of mimicking the biological activity of those compounds in mammals after dietary ingestion (Durand et al., 2011; Galano et al., 2017). In fact, various bioactivities, for example, neuroprotection and anti-inflammatory activities, have been reported for PhytoP in humans (Gonzalez Roldan et al., 2019; Martínez Sánchez et al., 2020; Minghetti et al., 2014). In contrast, the function of PhytoP and PhytoF in planta is still largely unknown. PhytoP have been reported to inhibit root growth (Mueller et al., 2008; Stotz et al., 2013). It has also been shown that the $A_{1}$ PhytoP displays similar biological activities as OPDA (12-oxophytodienoic acid), the precursor of the phytohormone jasmonic acid, inducing changes in gene expression that are mediated to a large part through TGAll transcription factors (Mueller et al., 2008, Stotz et al., 2013). In our work, the reactivity/toxicity of PhytoP in Arabidopsis leaves appears to be low compared to HNE or HHE (Figures 3 and S1). Also, none of the isoprostanoids tested here were found to activate AER gene expression. Possibly, signaling activities are restricted to specific PhytoP, involve other pathways than the xenobiotic detoxification response, or require much higher concentrations.

As a toxic compound, exogenous HNE was able to trigger the expression of detoxifying enzymes of the xenobiotic response such as AER (Figures 6 and S3). AER belongs to the cellular detoxification machinery controlled by the transcription regulator SCL14 (D'Alessandro et al., 2018). SCL14 interacts with TGAll transcription factors inducing a number of ANAC transcription factors and resulting in the activation of a panoply of detoxifying enzymes including AER (D'Alessandro et al., 2018). Nevertheless, under normal growth conditions, the SCL14-dependent pathway is weakly expressed and hence offers very limited protection against acute toxicity of exogenously 
applied HNE (Figure 6). However, the protective effect of the SCL14 pathway became evident in OE:SCL14 plants after activation by $\beta$-CC. Exposing whole OE:SCL14 plants to volatile $\beta$-CC (Figure S5B, C) or applying directly $\beta-C C$ on attached WT leaves (Figure 7) resulted in a strong induction of AER, and OE:SCL14 plants treated in such a way were found to be much more tolerant to HNE toxicity (Figures 8 and 9).

$\beta$-CC itself has a low toxicity causing little damage to leaves (Figure $8 \mathrm{C}$ ). Thus, the action of $\beta$-CC resembles the function of herbicide safeners, that is, chemicals of low toxicity able to induce enzymes involved in the detoxification and metabolization of herbicides (Castro et al., 2020; Riechers et al., 2010). Herbicide safeners offer important agricultural perspectives in alternative weed control strategies to increase herbicide selectivity in crops. Contrary to safeners that are exogenous, usually artificial molecules, $\beta-\mathrm{CC}$ is an endogenous compound naturally present in plant leaves. $\beta$-CC accumulates in plants under pro-oxidative conditions, such as high light or drought (D'Alessandro et al., 2019; Ramel et al., 2012), and enhances plant tolerance to those stress conditions, notably by recruiting the xenobiotic detoxification pathway (D'Alessandro et al., 2018). This study confirms that $\beta-C C$ is able to prime the detoxification process (Figure 6) and shows that this mechanism can target toxic compounds generated by lipid peroxidation such as HNE (Figures 7 and 8).

AER catalyzes the reduction of the $\alpha, \beta$-unsaturated bond of reactive carbonyls. Although Arabidopsis AER has a high affinity for HNE, it has a rather broad substrate spectrum acting on a variety of lipid carbonyls (Mano et al., 2005; Youn et al., 2006). Overexpression of Arabidopsis AER in tobacco was reported to increase tolerance to oxidative stress induced by methyl viologen or aluminum, by high light stress and by exogenously applied HNE (Mano et al., 2005; Yin et al., 2010). Together with our previous works (D'Alessandro et al., 2018; Ramel et al., 2012), the present study has shown that the apocarotenoid $\beta$-CC can lead to similar effects by up-regulating cellular detoxification and AER. The protective effect of $\beta$-CC was not observed in WT under our experimental conditions, presumably because the enhancement of cellular detoxification capacities was not enough to cope with the artificial treatments used in this study, which consist in direct application of high concentrations of pure HNE on leaves.

This study has illustrated the usefulness of autoluminescence imaging to monitor RCS-induced oxidative degradation of leaf tissues (Figures 3 and 6), even when visual symptoms and leaf necroses are hardly visible (Figure 10A). Actually, lipid oxidation appears to be an early event in the HNE-induced cell death since the luminescence intensity was the highest on leaf areas where damage was not yet visible (Figure 10A), and it decreased with the development of leaf necroses (Figure 10B). This could be related to degradation/metabolization of light-emitting lipid oxidation products in necrotic leaf tissues, but chlorophyll destruction could be an additional factor involved in the luminescence decrease (see below). Importantly, quantitative data can be obtained allowing comparisons between compounds with different toxicities (Figure 9).
Luminescence emission induced by HNE was found to occur in the red region of the visible spectrum. This observation is consistent with the spectral distribution of spontaneous light emission previously measured in chloroplasts and leaves (Hideg, 1993; Hideg et al., 1990; Kobayashi et al., 2006). It is different from the luminescence spectra of oxidized lipid solutions or mitochondria, which contain a blue component (Birtic et al., 2011; Hideg et al., 1991; Miyazawa et al., 1982; Timmins et al., 1997). Actually, the luminescence spectrum of Figure 3D resembles the spectrum of in vivo chlorophyll fluorescence/luminescence. It has been reported that in vitro triplet carbonyl species can transfer excitation energy to chlorophyll molecules (Bohne et al., 1986; Brunetti et al., 1983), leading to the suggestion that chlorophyll could be the final emitter of the autoluminescence signal from chlorophyllcontaining materials (Hideg, 1993). Actually, the absorption spectrum of chlorophyll coincides with the emission spectrum of oxidized lipids, particularly in the red domain, so that chlorophyll molecules can act as an absorbing screen. Leaf epidermis also contains various UV- and blue light-absorbing compounds (Hutzler et al., 1998), which could absorb photons at wavelengths below $500 \mathrm{~nm}$ (Merzlyak et al., 2008). Moreover, addition of chlorophyll $a$ to ALA after in vitro oxidation by ${ }^{1} \mathrm{O}_{2}$ was found to strongly enhance the luminescence emission (Birtic et al., 2011). Taken together, those findings support the idea that spontaneous photon emission by photosynthetic leaf tissues originates in fine from chlorophylls, presumably by energy transfer from excited lipid carbonyls to chlorophyll molecules, and this seems to be also the case for HNE-induced leaf luminescence. Energy transfer from triplet carbonyls to chlorophyll can occur through a triplet-singlet or triplet-triplet energy transfer mechanism, with triplet chlorophyll being converted to singlet chlorophyll by reverse inter-system crossing (Pospisil et al., 2019). The autoluminescence emission spectrum of Figure 3D is compatible with emission from the singlet excited state of chlorophyll, but its resolution is too low to draw a definite conclusion. In particular, ${ }^{1} \mathrm{O}_{2}$ can be formed from triplet chlorophyll and also during the lipid peroxidation process, and therefore we cannot exclude the participation of the dimol red emission of ${ }^{1} \mathrm{O}_{2}$ to the in vivo signal. Nevertheless, the lack of effect of sodium azide on the spontaneous photon emission from chloroplasts (Hideg \& Ibana, 1991) suggests that this contribution is very minor.

\section{ACKNOWLEDGMENTS}

This article is dedicated to the memory of Jean-Marc Ducruet to whom we are forever indebted for his generous assistance in the development of plant thermoluminescence techniques at CEA/Cadarache. The authors would like to thank Stefano D'Alessandro (Aix-Marseille University) for useful discussions, Amandine Rocher and Guillaume Reversat (IBMM, Montpellier) for their technical assistance in the targeted lipidomics, and Valérie Bultel-Poncé and Jean-Marie Galano (IBMM, Montpellier) for their assistance in the synthesis of isoprostanoids. The authors also thank Professor Michel Guichardant (INSA, Lyon) for his help with the RCS quantifications. Michel Havaux acknowledges fundings from ECCOREV and ANR. Marek Rac was supported by an European Union/ Palacky University grant (CZ.02.2.69/0.0/0.0/16_027/0008482). 


\section{AUTHOR CONTRIBUTIONS}

Marek Rac and Michel Havaux designed the study and carried out most of the experiments. Leonard Shumbe generated Arabidopsis pAER:LUC lines. Brigitte Ksas performed HOTE analyzes. Claire Vigor and Thierry Durand performed phytoprostane/phytofuran analyzes. Thierry Durand, Camille Oger, and Alexandre Guy synthesized pure RCS and isoprostanoids. Marek Rac, Brigitte Ksas, Claire Vigor, Thierry Durand, and Michel Havaux analyzed data and interpreted the results. Michel Havaux wrote the article with inputs from all co-authors.

\section{DATA AVAILABILITY STATEMENT}

Data Availability Statement: The data that support the findings of this study are publicly available and on request from the corresponding author

\section{ORCID}

Michel Havaux (D) https://orcid.org/0000-0002-6434-393X

\section{REFERENCES}

Beaugelin, I., Chevalier, A., D'Alessandro, S., Ksas, B. \& Havaux, M. (2020) Endoplasmic reticulum-mediated unfolded protein response is an integral part of singlet oxygen signalling in plants. The Plant Journal, 102, 1266-1280.

Beaugelin, I., Chevalier, A., D'Alessandro, S., Ksas, B., Novák, O., Strnad, M., et al. (2019) OXI1 and DAD regulate light-induced cell death antagonistically through jasmonate and salicylate levels. Plant Physiology, 180, 1691-1708.

Birtic, S., Ksas, B., Genty, B., Mueller, M.J., Triantaphylidès, C. \& Havaux, M. (2011) Using spontaneous photon emission to image lipid oxidation patterns in plant tissues. The Plant Journal, 67, 1103-1115.

Biswas, M.S. \& Mano, J. (2015) Lipid peroxide-derived short chain carbonyls mediate hydrogen peroxide-induced and salt-induced programmed cell death in plants. Plant Physiology, 168, 885-898.

Bohne, C., Campa, A., Cilento, G., Nassi, L. \& Villablanca, M. (1986) Chlorophyll: an efficient detector of electronically excited species in biochemical systems. Analytical Biochemistry, 155, 1-9.

Bour, A., Kruglik, S.G., Chabanon, M., Rangamani, P., Puff, N. \& Bonneau, S. (2019) Lipid unsaturation properties govern the sensitivity of membranes to photoinduced oxidative stress. Biophysical Journal, $116,910-920$.

Brunetti, I., Cilento, G. \& Nassi, L. (1983) Energy transfer from enzymatically-gerenerated triplet species to acceptors in micelles. Photochemistry and Photobiology, 38, 511-519.

Castro, E., Pucci, C., Duarte, S., Burgos, N. \& Tseng, T. (2020) Improved herbicide selectivity in tomato by safening action of benoxacor and fenclorim. Weed Technology, (in press). https://doi.org/10.1017/wet. 2020.30.

Chan, T., Shimizu, Y., Pospisil, P., Nijo, N., Fujiwara, A., Taninaka, Y., et al. (2012) Quality control of photosystem II: lipid peroxidation accelerates photoinhibition under excessive illumination. PLoS One, 7, e52100.

Choudhary, S., Xiao, T., Srivastava, S., Zhang, W., Chan, L.L., Vergara, L.A., et al. (2005) Toxicity and detoxification of lipid-derived aldehydes in cultured retinal pigmented epithelial cells. Toxicology and Applied Pharmacology, 204, 122-134.

Cuyamendous, C., Leung, K.S., Durand, T., Lee, J.C.-Y., Oger, C. \& Galano, J.-M. (2015) Synthesis and discovery of phytofurans: metabolites of $\alpha$-linolenic acid peroxidation. Chemical Communications, 51, 15696-15699.

Dalal, M. \& Khanna-Chopra, R. (1999) Lipid peroxidation is an early event in necrosis of wheat hybrid. Biochemical and Biophysical Research Communications, 262, 109-112.
D'Alessandro, S. \& Havaux, M. (2019) Sensing $\beta$-carotene oxidation in photosystem II to master plant stress tolerance. The New Phytologist, 223, 1776-1783.

D'Alessandro, S., Ksas, B. \& Havaux, M. (2018) Decoding ß-cyclocitral-mediated retrograde signaling reveals the role of a detoxification response in plant tolerance to photooxidative stress. Plant Cell, 30, 2495-2511.

D'Alessandro, S., Mizokami, Y., Légeret, B. \& Havaux, M. (2019) The apocarotenoid $\beta$-cyclocitric acid elicits drought tolerance in plants. iscience, 19, 461-473.

Douce, R. \& Joyard, J. (1980) Plant galactolipids. In: Stumpf, P.K. (Ed.) The biochemistry of plants, Vol. 4. New York: Academic Press, pp. 321-362.

Ducruet, J.-M. (2003) Chlorophyll thermoluminescence of leaf discs: simple instruments and progress in signal interpretation open the way to new ecophysiological indicators. Journal of Experimental Botany, 54, 2419-2430.

Duran, N. \& Cadenas, E. (1987) The role of singlet oxygen and triplet carbonyls in viological systems. Reviews of Chemical Intermediates, 8, 147-187.

Durand, T., Bultel-Poncé, V., Guy, A., El Fabgour, S., Rossi, J.C. \& Galano, J. M. (2011) Isoprostanes and phytoprostanes: bioactive lipids. Biochimie, 93, 52-60.

Farmer, E.E. \& Mueller, M.J. (2013) ROS-mediated lipid peroxidation and RES-activated signaling. Annual Review of Plant Biology, 64, 429-450.

Fode, B., Siemsen, T., Thurow, C., Weigel, R. \& Gatz, C. (2008) The Arabidopsis GRAS protein SCL14 interacts with class II TGA transcription factors and is essential for the activation of stress-inducible promoters. Plant Cell, 20, 3122-3135.

Galano, J.M., Lee, Y.Y., Oger, C., Vigor, C., Vercauteren, J., Durand, T., et al. (2017) Isoprostanes, neuroprostanes and phytoprostanes: an overview of 25 years of research in chemistry and biology. Progress in Lipid Research, 68, 83-108.

Gonzalez Roldan, N., Engel, R., Düpow, S., Jakob, K., Koops, F., Orinska, Z., et al. (2019) Lipid mediators from Timothy grass pollen contribute to the effector phase of allergy and prime dentritic cells for glycerolipid presentation. Frontiers in Immunology, 10, 974.

Havaux, M. (2003) Spontaneous and thermoinduced photon emission: new methods to detect and quantify oxidative stress in plants. Trends in Plant Science, 8, 409-413.

Havaux, M. (2020) $\beta$-Cyclocitral and derivatives: emerging molecular signals serving multiple biological functions. Plant Physiology and Biochemistry, 155, 35-41.

Havaux, M., Eymery, F., Porfirova, S., Rey, P. \& Dörmann, P. (2005) Vitamin $\mathrm{E}$ protects against photoinhibition and photooxidative stress in Arabidopsis thaliana. Plant Cell, 17, 3451-3469.

Havaux, M., Genty, B. \& Triantaphylides, C. (2006) Autoluminescence imaging: a non-invasive tool for mapping oxidative stress. Trends in Plant Science, 11, 480-484.

Hideg, E. (1993) On the spontaneous ultraweak light emission of plants. Journal of Photochemistry and Photobiology, 18, 239-244.

Hideg, E. \& Ibana, H. (1991) Biophoton emission (ultraweak photoemission) from dark adapted spinach chloroplasts. Photochemistry and Photobiology, 53, 137-142.

Hideg, E., Kobayashi, M. \& Inaba, H. (1990) Utraweak photoemission from dark-adapted leaves and isolated chloroplast. FEBS Letters, 275, 121-124.

Hideg, E., Kobayashi, M. \& Inaba, H. (1991) Spontaneous ultraweak light emission from respiring spinach leaf mitochondria. Biochimica et Biophysica Acta, 1098, 27-31.

Huang, J., Zhao, X. \& Chory, J. (2019) The Arabidopsis transcriptome responds specifically and dynamically to high light stress. Cell Reports, 29, 4186-4199.

Hutzler, P., Fischbach, R., Heller, W., Jungblut, T.P., Reuber, S., Schmitz, R., et al. (1998) Tissue localization of phenolic compounds in plants by confocal laser scanning microscopy. Journal of Experimental Botany, 49, 953-965.

Imbusch, R. \& Mueller, M.J. (2000) Formation of isoprostane $F_{2}$-like compounds (phytoprostanes $F_{0}$ ) from $\alpha$-linolenic acid in plants. Free Radical Biology and Medicine, 28, 720-726. 
Johnson, M.P., Havaux, M., Triantaphylides, C., Ksas, B., Pascal, A.A., Robert, B., et al. (2007) Elevated zeaxanthin bound to oligomeric LHCII enhances the resistance of Arabidopsis to photooxidative stress by a lipid-protective, antioxidant mechanism. The Journal of Biological Chemistry, 282, 22605-22618.

Karimi, M., De Meyer, B. \& Hilson, P. (2005) Modular cloning in plant cells. Trends in Plant Science, 10, 103-105.

Kobayashi, M., Sasaki, K., Enomoto, M. \& Ehara, Y. (2006) Highly sensitive determination of transient generation of biophotons during hypersensitive response to cucumber mosaic virus in cowpea. Journal of Experimental Botany, 58, 465-472.

Ksas, B. \& Havaux, M. (2020) Determination of ROS-induced lipid peroxidation by HPLC-based quantification of hydroxy polyunsaturated fatty acids. Methods in Molecular Biology in press.

Levesque-Tremblay, G., Havaux, M. \& Ouellet, F. (2009) The chloroplastic lipocalin AtCHL prevents lipid peroxidation and protects Arabidopsis against oxidative stress. The Plant Journal, 60, 691-702.

Li, B., Fang, J., Singh, R.M., Zi, H., Lv, S., Liu, R., et al. (2020) FATTY ACID DESATURASE 5 is required to induce autoimmune responses in gigantic chloroplast mutants of Arabidopsis. Plant Cell, 32, 3240-3255.

Li-Beisson, Y., Shorrosh, B., Beisson, F., et al. (2013) Acyl-lipid metabolism. The Arabidopsis Book, 2013, 11. https://doi.org/10.1199/tab.0161.

Mano, J., Belles-Boix, E., Babiychuk, E., Inzé, D., Torii, Y., Hiraoka, E., et al. (2005) Protection against photooxidative injury of tobacco leaves by 2-alkenal reductase. Detoxication of lipid peroxide-derived reactive carbonyls. Plant Physiology, 139, 1773-1783.

Mano, J., Biswas, M.S. \& Sugimoto, K. (2019) Reactive carbonyl species: a missing link in ROS signaling. Plants (Basel), 8, 391.

Mano, J., Tokushige, K., Mizoguchi, H., Fuji, H. \& Khorobrykh, S. (2010) Accumulation of lipid peroxide-derived, toxic alpha,beta-unsaturated aldehydes (E)-2-pentenal, acrolein and (E)-2-hexenal in leaves under photoinhibitory illumination. Plant Biotechnology, 27, 193-197.

Martínez Sánchez, S., Domínguez-Perles, R., Montoro-García, S., Gabaldón, J. A., Guy, A., Durand, T., et al. (2020) Bioavailable phytoprostanes and phytofurans from Gracilaria longissima have anti-inflammatory effects in endothelial cells. Food and Function, 11, 5166-5178.

Merzlyak, M.N., Melo, T.B. \& Naqvi, K.R. (2008) Effects of antocyanins, carotenoids, and flavonols on chlorophyll fluorescence excitation spectra in apple fruit: signature analysis, assessment, modelling, and relevance to photoprotection. Journal of Experimental Botany, 59, 349-359.

Michalski, M.-C., Calzada, C., Makino, A., Michaud, S. \& Guichardant, M. (2008) Oxidation products of polyunsaturated fatty acids in infant formulas compared to human milk - a preliminary study. Molecular Nutrition \& Food Research, 52, 1478-1485.

Minghetti, L., Salvi, R., Salvatori, M.L., Ajmone-Cat, M.A., De Nuccio, C., Visentin, S., et al. (2014) Nonenzymatic oxygenated metabolites of $\alpha$-linolenic acid B1- and L1-phytoprostanes protect immature neurons from oxidant injury and promote differentiation of oligodendrocyte progenitors through PPAR- $\gamma$ activation. Free Radical Biology and Medicine, 73, 41-50.

Miyazawa, T., Usuki, R. \& Kaneda, T. (1982) Spetroscopic abalysis of the weak light generated in autoxidation of linseed oil. Agricultural and Biological Chemistry, 46, 1671-1672.

Montillet, J.-L., Cacas, J.-L., Garnier, L., Montané, M.-H., Douki, T., Bessoule, J.-J., et al. (2004) The upstream oxylipin profile of Arabidopsis thaliana: a tool to scan for oxidative stresses: Lipid peroxidation in Arabidopsis. The Plant Journal, 40, 439-451.

Mueller, S., Hilbert, B., Dueckershoff, K., Roitsch, T., Krischke, M., Mueller, M.J., et al. (2008) General detoxification and stress responses are mediated by oxidized lipids through TGA transcription factors in Arabidopsis. Plant Cell, 20, 768-785.

Oger, C., Brinkmann, Y., Bouazzaoui, S., Durand, T. \& Galano, J.M. (2008) Stereocontrolled access to isoprostanes via a Bicyclo[3.3.0]octene framework. Organic Letters, 10, 5087-5090.
Pohl, E.E. \& Jovanovic, O. (2019) The role of phosphatidylethanolamine adducts in modification of the activity of membrane proteins under oxidative stress. Molecules (MDPI), 24, 4545.

Pospisil, P., Prasad, A. \& Rac, M. (2019) Mechanism of the formation of electronically excited species in oxidative metabolic processes: role of reactive oxygen species. Biomolecules (MDPI), 9, 258.

Prasad, A. \& Pospísil, P. (2013) Towards the two-dimensional imaging of spontaneous ultra-weak photon emission from microbial, plant and animal cells. Scientific Reports, 3, 1211.

Ramel, F., Birtic, S., Ginies, C., Soubigou-Taconnat, L., Triantaphylidès, C. \& Havaux, M. (2012) Carotenoid oxidation products are stress signals that mediate gene responses to singlet oxygen in plants. Proceedings of the National Academy of Sciences, 109, 5535-5540.

Ramel, F., Ksas, B., Akkari, E., Mialoundama, A.S., Monnet, F., KriegerLiszkay, A., et al. (2013) Light-induced acclimation of the Arabidopsis chlorina1 mutant to singlet oxygen. Plant Cell, 25, 1445-1462.

Repetto, G., Zurita, J.L., Roncel, M. \& Ortega, J.M. (2015) Thermoluminescence as a complementary technique for the toxicological evaluation of chemicals in photosynthetic organisms. Aquatic Toxicology, 158, 88-97.

Repetto, M., Ossani, G., Monserrat, A. \& Boveris, A. (2010) Oxidative damage: the biochemical mechanism of cellular injury and necrosis in choline deficiency. Experimental and Molecular Pathology, 88, 143-149.

Riechers, D.E., Kreuz, K. \& Zhang, Q. (2010) Detoxification without intoxication: herbicide safeners activate plant defense gene expression. Plant Physiology, 153, 3-13.

Roach, T., Baur, T., Stöggl, W. \& Krieger-Liszkay, A. (2017) Chlamydomonas reinhardtii responding to high light: a role for 2-propenal (acrolein). Physiologia Plantarum, 161, 75-87.

Roach, T., Stöggl, W., Baur, T. \& Kranner, I. (2018) Distress and eustress of reactive electrophiles and relevance to light stress acclimation via stimulation of thiol/disulphide-based redox defences. Free Radical Biology and Medicine, 122, 65-73.

Shumbe, L., Chevalier, A., Legeret, B., Taconnat, L., Monnet, F. \& Havaux, M. (2016) Singlet oxygen-induced cell death in Arabidopsis under high-light stress is controlled by OXI1 kinase. Plant Physiology, 170, 1757-1771.

Skotnica, J., Gilbert, M., Weingart, I. \& Wilhelm, C. (2003) Thermoluminescence as a tool for monitoring ozone-stressed plants. Environmental Pollution, 123, 15-20.

Soulère, L., Queneau, Y. \& Doutheau, A. (2007) An expedicious synthesis of 4-hydroxy-2(E)-nonenal (4-HNE) its dimethyl acetal and of related compounds. Chemistry and Physics of Lipids, 150, 239-243.

Sousa, B.C., Pitt, A.R. \& Spickett, C.M. (2017) Chemistry and analysis of HNE and other prominent carbonyl-containing lipid oxidation compounds. Free Radical Biology and Medicine, 111, 294-308.

Stotz, H., Mueller, S., Zoeller, M., Mueller, M.J. \& Berger, S. (2013) TGA transcription factors and jasmonate-independent COI1 signalling regulate specific plant responses to reactive oxylipins. Journal of Experimental Botany, 64, 963-975.

Timmins, G.S., dos Santos, R.E., Whitwood, A.C., Catalani, L.H., Di Mascio, P., Gilbert, B.C., et al. (1997) Lipid peroxidation-dependent chemiluminescence from the cyclization of alkylperoxyl radicals to dioxetane radical intermediates. Chemical Research in Toxicology, 10, 1090-1096.

Vavilin, D.V. \& Ducruet, J.-M. (1998) The origin of $115-130^{\circ} \mathrm{C}$ thermoluminescence bands in chlorophyll-containing material. Photochemistry and Photobiology, 68, 191-198.

Vigor, C., Reversat, G., Rocher, A., Oger, C., Galano, J.M., Vercauteren, J., et al. (2018) Isoprostanoids quantitative profiling of marine red and brown macroalgae. Food Chemistry, 268, 452-462.

Wei, X. \& Yin, H. (2015) Covalent modification of DNA by $\alpha, \beta$-unsaturated aldehydes derived from lipid peroxidation: recent progress and challenges. Free Radical Research, 49, 905-917. 
Yin, L., Mano, J., Wang, S., Tsuji, W. \& Tanaka, K. (2010) The involvement of lipid peroxide-derived aldehydes in aluminum toxicity of tobacco roots. Plant Physiology, 152, 1406-1417.

Yonny, M.E., Rodriguez Torresi, A., Cuyamendous, C., Reversat, G., Oger, C., Galano, J.M., et al. (2016) Thermal stress in melon plants: phytoprostanes and phytofurans as oxidative stress biomarkers and the effect of antioxidant supplementation. Journal of Agricultural and Food Chemistry, 64, 8296-8304.

Youn, B., Kim, S.-J., Moinuddin, S.G.A., Lee, C., Bedgar, D.L., Harper, A. R., et al. (2006) Mechanistic and structural studies of apoform, binary, and ternary complexes of the Arabidopsis alkenal double bond reductase At5g16970. The Journal of Biological Chemistry, 281, 40076-40088.

\section{SUPPORTING INFORMATION}

Additional supporting information may be found online in the Supporting Information section at the end of this article. 